\title{
Designing a Functional Beverage Blend for Optimal Antioxidant Activity and its Storage Stability
}

\author{
Hamza Tariq ${ }^{1}$, Imran Hayat ${ }^{1}$, Saima Rafiq $^{1 *}$, Aqsa Qayyum ${ }^{2}$ and Sohrab Qayyum ${ }^{1}$
}

${ }^{1}$ Department of Food Sciecne and Technology, Univrsity of the Poonch Rawalakot-12350, Azad Kashmir, Pakistan; ${ }^{2}$ Food Science Research Institute, National Agricultural Research Centre, Islamabad-44000, Pakistan.

Abstract | The present study was designed to formulate a new antioxidant rich ready-to-serve (RTS) beverage by the combination of different ratios of apple and autumn olive juice $\left(\mathrm{T}_{1=}\right.$ Apple $100 \%+$ Autumn olive $0 \%, \mathrm{~T}_{2}$ Apple $80 \%+$ Autumn olive 20\%, $\mathrm{T}_{3=}$ Apple 60\% + Autumn olive 40\%, $\mathrm{T}_{4=}$ Apple $40 \%+$ Autumn olive 60\%, $\mathrm{T}_{5=}$ Apple 20\% + Autumn olive 80\%, $\mathrm{T}_{6=}$ Apple 0\% + Autumn olive 100\%) and to study its physico-chemical profile ( $\mathrm{pH}$, acidity, total soluble solids (TSS), reducing sugars, non-reducing sugars, total sugars, vitamin $\mathrm{C}$ ), antioxidant activity, total phenolics, and sensory evaluation (color, flavor, taste, overall acceptability) during storage (90 days) at ambient temperature for consumer acceptability. An increase in titratable acidity, vitamin $\mathrm{C}$, total phenolics and antioxidant activity was observed with increasing the concentration of autumn olive in the beverage blends while a decreasing trend was observed for $\mathrm{pH}$, reducing sugars, non-reducing sugars and total sugars. Organoleptic parameters such as color, flavor, taste and overall acceptability significantly ( $p$ $<0.05$ ) influenced. The TSS, acidity, reducing sugars and total sugars content increased whereas $\mathrm{pH}$, ascorbic acid, antioxidant activity, total phenolics and non-reducing sugar content decreased during storage of 90 days. Overall, the blended drink having 40\% apple and 60\% autumn olive juice RTS was highly acceptable.

Received | September 20, 2019; Accepted | February 26, 2020; Published | July 26, 2020

*Correspondence | Saima Rafiq, Department of Food Sciecne and Technology, Univrsity of the Poonch Rawalakot-12350, Azad Kashmir, Pakistan; Aqsa Qayyum, Food Science Research Institute, National Agricultural Research Centre, Islamabad-44000, Pakistan; Email: saimaft2009@ gmail.com; aqsachatha@gmail.com

Citation | Tariq, H., I. Hayat, S. Rafiq, A. Qayyum and S. Qayyum. 2020. Designing a functional beverage blend for optimal antioxidant activity and its storage stability. Pakistan Journal of Agricultural Research, 33(3): 516-526.

DOI | http://dx.doi.org/10.17582/journal.pjar/2020/33.3.516.526

Keywords | Fruits blend, RTS beverage, Phenolics, Antioxidant activity

\section{Introduction}

$\mathrm{C}$ onsumers are well aware about the healthy diet and healthy lifestyle. Dietary guidelines recommend that intake of fruits and vegetables may lower the risk of various degenerative outbreaks (cardiovascular diseases, inflammation, aging related disorders). Therefore, utilization of fruits for the product development is one of the prime objectives of different food industries. Incorporation of fruits into the diet of the consumers in the form of fruit juices is an attractive and easiest option for the food industry (Petruzzi et al., 2017). In modern fruit beverage processing, blending technology is an important tool for the development of superior quality beverage having sensory, nutritional and medicinal properties of two or more plant species (Bhagwan and Awadhesh, 2014). The main factors that attract consumers for such blended beverage includes attractive appearance, appealing flavor, nutrients retention, medicinal values and other organoleptic qualities which meet the consumer preferences and hence improves marketability of new blended products. The readyto-serve (RTS) beverages are very popular among different consumers of all age groups because these are easy to carry and consume (Nidhi et al., 2008).

Apple (Malus domestica) is the most vital fruit 
produced in world which belongs to family Rosaceae and subfamily Pomoideae. Numerous apple varieties are grown in different parts of the world at higher altitudes but the apple varieties grown at altitude above $2000 \mathrm{~m}$ are considered superior quality wise due to more number of chilling hours (Koutsos and Lovegrove, 2015). The production of apple in the world is 63 million tones/annum. Apple is grown mostly in China, producing about $41 \%$ of the world's apples (Ntakyo et al., 2015). In Azad Kashmir, certain low chilling fresh varieties have been introduced like Enna, Tropical beauty and Einsheimer. The Banki variety of apple is widely produced in Rawalakot, Azad Kashmir, but it is not preferred by the consumers for its objectionable appearance due to fungal attack. This underutilized variety of apple can be best utilized by its value addition to produce different food products (Shakir et al., 2008).

Apple comprises a significant part of the human diet, from dietary and medical prospective. Its significance in daily diet is obvious from an old age proverb "an apple a day keeps the doctor away" as they are a good source of carbohydrates, minerals, vitamins, dietary fiber, and biologically active compounds ( $\mathrm{Wu}$ et al., 2007; Sluis et al., 2002). Many studies have associated utilization of apples with decreased risk of diseases like cancers, heart disease, asthma, obesity and diabetes (Vinson et al., 2001). These antioxidants restrain propagation, reduce lipid oxidation, and lessen cholesterol. Phytochemicals present in apple are Catechin, Quercetin, Phloridzin and Chlorogenic acid, which exhibit anti-oxidant activity (Boyer and Liu, 2004).

Autumn olive is also an important fruit that belongs to the family Elaegnaceae and is also called cardinal olive or autumn olive (Sabir et al., 2003). This plant was introduced in 1830s from East Asia as a decorative plant. Elaeagnaceae, is inherent to China, Japan and Korea, and is also presented in Afghanistan and India. Additional communal names for the plant include Autumn Elaeagnus, Asiatic Oleaster, Umbellate Oleaster, Aki-gumi and Japanese Silverberry (Parmar and Kaushal, 1982; Ahmad et al., 2006; Minhas et al., 2013). It contains a variety of phytochemicals having antioxidant activity and an extensive array of flavonoids such as anthocyanins, flavonoids, proanthocyanidins, flavonols, phenolic acids and isoflavones (Fordham et al., 2003; Guo et al., 2009). Various forms of carotenoids such as lycopene, $\alpha$-cryptoxanthin, $\beta$-cryptoxanthin, $\beta$-carotene, lutein, phytoene, and phytofluene are also present in it (Wang and Fordham 2007). It has been marketed as a functional ingredient in diets primarily for its abundance of lycopene, which may have antioxidant and anti-carcinogenic activity, and hepatoprotective effects. The utilization of autumn olive has great association with many physiological and health benefits such as prevention of cardiovascular disease, obesity, diabetes mellitus, hepatitis, fracture, injury, diarrhea and cancer (Perveen et al., 2015; Pinto et al., 2013; Sun et al., 2002). Autumn olive juice is blended with apple juice because of its tartness, poor taste and flavor which was not acceptable for consumers. Some fruits are rich in nutrients and medicinal properties, but are not accepted due to high acidity or poor taste. These fruits can be blended with other fruits to improve their acceptability and make use of available nutrients. Keeping in view the nutritional, medicinal and functional attributes of apple and autumn olive, the current study was conducted to develop apple and autumn olive RTS antioxidant rich beverages. Natural spices were also added for flavors and other desirable characteristics of product. The prepared product was studied for its safety and stability under ambient storage conditions for 90-days.

\section{Materials and Methods}

\section{Preparation of RTS beverages blends}

The freshly ripe apple and autumn olive fruits were collected and washed thoroughly in running tap water. Fruits were peeled and trimmed with the help of stainless steel knife and then introduced to a juicer machine where extraction of juice was carried out. After obtaining juice, these were passed through muslin cloth to remove impurities and seeds. The blended beverages were prepared by using different combinations of apple and autumn olive as mentioned here; $\mathrm{T}_{1}=$ Apple $100 \%+$ Autumn olive $0 \%, \mathrm{~T}_{2}=$ Apple $80 \%+$ Autumn olive $20 \%, \mathrm{~T}_{3}=$ Apple $60 \%+$ Autumn olive $40 \%, \mathrm{~T}_{4}=$ Apple $40 \%+$ Autumn olive $60 \%, \mathrm{~T}_{5}=$ Apple $20 \%+$ Autumn olive $80 \%, \mathrm{~T}_{6}$ $=$ Apple $0 \%+$ Autumn olive $100 \%$. The production of blended beverage is shown in Figure 1. Each treatment is prepared up to $400 \mathrm{~mL}$ in volume with juice concentration $300 \mathrm{~mL}$, water $100 \mathrm{~mL}$, sucrose $(6-12 \mathrm{~g})$ is added to adjust the level of Brix. Citric acid $(0.02 \%)$ as well as Potassium metabisulfite $(0.1 \%)$ is added as preservative. Blended beverages were then pasteurized and stored in pre sterilized 
PET bottles at room temperature and were analyzed for different physicochemical, antioxidant and for sensory parameters at $0,15,30,45,60,75$ and 90 days of storage.

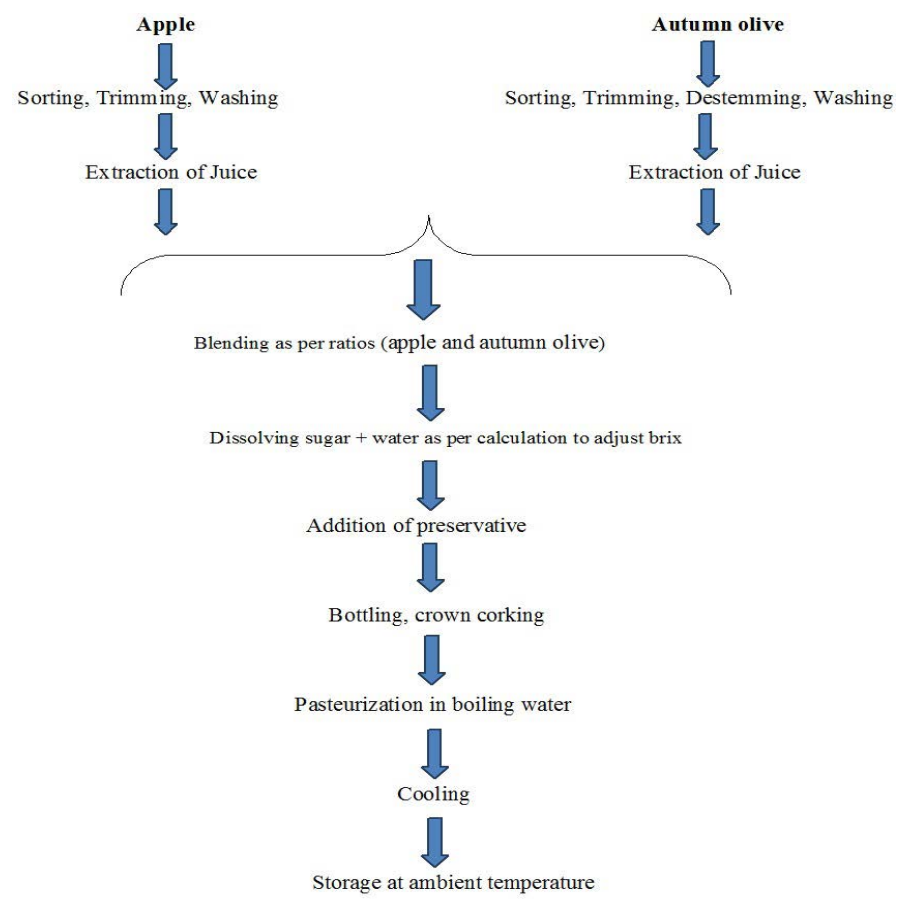

Figure 1: Preparation of RTS beverage blend.

\section{pH, ${ }^{\circ}$ Brix, titratable acidity (TA) and ascorbic acid}

The $\mathrm{pH}$ was determined with a digital $\mathrm{pH}$ meter (Hanna pH-meter HI 9021 m Germany) at 20 ${ }^{\circ} \mathrm{C}$ as described in AOAC (2006). The ${ }^{0}$ Brix (total soluble solids) were determined by measurement of the refractive index with a digital refractrometer (JEN way) at $20^{\circ} \mathrm{C}$ as reported in AOAC (2006). Titratable acidity acidity was determined by means of a potentiometric titration of the acidity of the juice, with a solution of $0.1 \mathrm{M} \mathrm{NaOH}$ as mentioned in AOAC (2006). It was determined by means of a three replicates. The results were expressed as $\mathrm{g} / 100 \mathrm{ml}$. Ascorbic acid was determined by using 2, 6dichlorophenol indophenols as decolourizing agent by ascorbic acid in juice sample AOAC (2006).

\section{Determination of reducing; non-reducing and total sugar} Reducing sugar, non reducing sugar and total sugar contents of the beverage samples were determined by method as reported in AOAC (2006).

\section{Determination of total phenolics}

Total phenolic content of beverage sample were measured spectrophotometrically according to method as described by Singleton et al. (1999). For this purpose, 10\% Folin- Ciocalteau's Reagent (2.5
$\mathrm{mL})$ and $7.5 \%$ sodium carbonate solution $(2 \mathrm{~mL})$ were taken and beverage sample $(0.5 \mathrm{~mL})$ was added. This mixture was incubated at $45^{\circ} \mathrm{C}$ for $40 \mathrm{~min}$ and the absorbance was calculated at $765 \mathrm{~nm}$ in the spectrophotometer. Total phenolic contents were measured by using following formula.

$$
\text { Total phenols }\left(\frac{\mathrm{mg}}{\mathrm{g}}\right)=\frac{1.13 \times(\text { absorbance })}{\text { weight of sample }}
$$

Where; "1.13" is the calibration factor obtained from standard curve (Gallic acid).

\section{Antioxidant activity}

Antioxidant activity of the beverage samples were determined by DPPH method as described by Williams et al. (1995). For this purpose 0.5 $\mathrm{mL}$ beverage sample was prepared and mixed with $1 \mathrm{~mL}$ of a freshly prepared DPPH solution $(0.25 \mathrm{Mm})$ in methanol and $1 \mathrm{~mL}$ of ethanol in test tube. The reaction mix was permitted to react completely at ambient temperature for $30 \mathrm{~min}$ and absorbance of the resulting mixture was measured spectrophotometrically (METROLAB 1600 DR) at $517 \mathrm{~nm}$ and converted to percentage DPPH radical scavenging activity. The DPPH scavenging activity was calculated by using following formula.

$$
\text { DPPH scavenging activity }(\%)=\left(A_{0}-\frac{A_{s}}{A_{0}}\right) \times 100
$$

$A_{0}$ is the absorbance of the control; $A s$ is the absorbance of the sample.

\section{Organoleptic evaluation}

Organoleptic evaluation of beverage samples were carried out by panel of seven judges (Larmond, 1977). These judges were asked to rate beverage samples for color, taste, flavor and overall acceptability on the basis of 9-point Hedonic scale ranging from liked extremely (9) to disliked extremely (1). Taste is feeling made when an ingredient in the mouth reacts chemically with taste receptor cells situated on the taste buds of tongue. The gustatory cortex is accountable for the perception of taste. Flavor is sensory impression of food or other material and is determined by taste and smell. The flavor of food can be varied with natural or artificaial flavoratnts which affect the senses. These differences between taste and flavor were discussed with panel and each of them was detected by following the methodology as mentioned by Larmond, 1977. 
Table 1: Effect of treatments (antioxidant rich RTS beverage) on physico-chemical, total phenolics, and antioxidant activity (DPPH).

$\begin{array}{lllllll}\text { Parameters } & \mathbf{T}_{1} & \mathbf{T}_{2} & \mathbf{T}_{3} & \mathbf{T}_{4} & \mathbf{T}_{5} & \mathbf{T}_{6} \\ \mathrm{pH} & 4.85 \pm 0.12 \mathrm{~A} & 4.43 \pm 0.16 \mathrm{~B} & 4.29 \pm 0.11 \mathrm{~B} & 4.23 \pm 0.01 \mathrm{~B} & 3.92 \pm 0.23 \mathrm{C} & 3.81 \pm 0.07 \mathrm{C} \\ \text { Titratable acidity }(\%) & 0.62 \pm 0.17 \mathrm{~F} & 0.73 \pm 0.03 \mathrm{E} & 0.84 \pm 0.03 \mathrm{D} & 0.95 \pm 0.01 \mathrm{C} & 1.00 \pm 0.00 \mathrm{~B} & 1.30 \pm 0.02 \mathrm{~A} \\ \text { TSS }\left({ }^{\circ} \mathrm{Brix}\right) & 14.6 \pm 1.03 \mathrm{~A} & 14.7 \pm 1.11 \mathrm{~A} & 14.8 \pm 1.03 \mathrm{~A} & 14.6 \pm 1.75 \mathrm{~A} & 14.50 \pm 1.09 \mathrm{~A} & 14.50 \pm 1.81 \mathrm{~A} \\ \text { Vitamin C }(\mathrm{mg} / 100 \mathrm{~g}) & 5.8 \pm 1.11 \mathrm{E} & 6.5 \pm 0.76 \mathrm{D} & 6.8 \pm 1.12 \mathrm{DC} & 8.9 \pm 0.88 \mathrm{C} & 9.50 \pm 0.21 \mathrm{~B} & 10.60 \pm 0.76 \mathrm{~A} \\ \text { Total phenolics }(\mathrm{mg} / \mathrm{g}) & 5.2 \pm 0.32 \mathrm{~F} & 9.2 \pm 1.34 \mathrm{E} & 14.1 \pm 1.08 \mathrm{D} & 15.5 \pm 1.19 \mathrm{C} & 17.60 \pm 1.87 \mathrm{~B} & 21.30 \pm 2.01 \mathrm{~A} \\ \text { Reducing sugars }(\%) & 7.47 \pm 0.11 \mathrm{~A} & 7.36 \pm 0.13 \mathrm{~A} & 7.32 \pm 0.11 \mathrm{AB} & 7.11 \pm 0.03 \mathrm{BC} & 6.96 \pm 0.14 \mathrm{C} & 4.80 \pm 0.76 \mathrm{D} \\ \text { Non Reducing sugars }(\%) & 2.70 \pm 0.02 \mathrm{~A} & 2.63 \pm 0.01 \mathrm{AB} & 2.54 \pm 0.01 \mathrm{~B} & 2.25 \pm 0.01 \mathrm{C} & 1.96 \pm 0.03 \mathrm{D} & 1.67 \pm 0.01 \mathrm{E} \\ \text { Total sugars }(\%) & 10.6 \pm 1.04 \mathrm{~A} & 10.0 \pm 1.12 \mathrm{AB} & 9.8 \pm 1.08 \mathrm{~B} & 9.6 \pm 1.13 \mathrm{BC} & 8.90 \pm 1.06 \mathrm{C} & 6.4 \pm 1.08 \mathrm{D} \\ \text { Antioxidant activity }(\%) & 24.5 \pm 2.06 \mathrm{~F} & 27.6 \pm 2.11 \mathrm{E} & 33.8 \pm 2.56 \mathrm{D} & 37.2 \pm 2.11 \mathrm{C} & 43.50 \pm 2.01 \mathrm{~B} & 50.10 \pm 1.98 \mathrm{~A} \\ \text { Color } & 5.2 \pm 1.01 \mathrm{C} & 5.5 \pm 1.15 \mathrm{C} & 6.3 \pm 1.13 \mathrm{~B} & 6.4 \pm 0.32 \mathrm{~B} & 6.50 \pm 1.16 \mathrm{~B} & 7.00 \pm 0.78 \mathrm{~A} \\ \text { Flavor } & 5.3 \pm 1.03 \mathrm{~B} & 5.4 \pm 1.04 \mathrm{~B} & 6.0 \pm 1.08 \mathrm{AB} & 6.3 \pm 0.11 \mathrm{~A} & 4.90 \pm 1.00 \mathrm{C} & 4.40 \pm 0.14 \mathrm{D} \\ \text { Taste } & 6.1 \pm 1.11 \mathrm{D} & 6.5 \pm 0.15 \mathrm{C} & 6.9 \pm 1.00 \mathrm{~B} & 7.4 \pm 0.47 \mathrm{~A} & 5.30 \pm 1.32 \mathrm{E} & 5.00 \pm 1.05 \mathrm{E} \\ \text { Over all acceptability } & 6.37 \pm 1.14 \mathrm{~B} & 6.50 \pm 0.89 \mathrm{~B} & 6.63 \pm 0.32 \mathrm{~B} & 7.46 \pm 1.06 \mathrm{~A} & 5.73 \pm 1.15 \mathrm{C} & 4.92 \pm 1.74 \mathrm{D}\end{array}$

Letters shows means of different treatments and same letters shown a non-significant results while different letters show significant interaction.

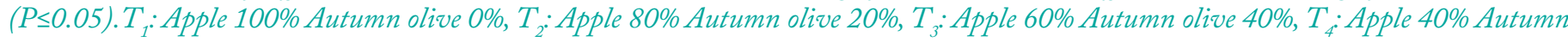
olive 60\%, $T_{5}$ : Apple 20\% Autumn olive 80\%, $T_{6}$ : Apple 100\% Autumn olive 0\%.

Table 2: Physico-chemical, total phenolics, and antioxidant activity (DPPH) of antioxidant rich RTS beverage during storage.

$\begin{array}{llllllll}\text { Parameters } & \mathbf{0} \text { day } & \mathbf{1 5} \text { days } & \mathbf{3 0} \text { days } & \mathbf{4 5} \text { days } & \mathbf{6 0} \text { days } & \mathbf{7 5} \text { days } & \mathbf{9 0} \text { days } \\ \mathrm{pH} & 4.64 \pm 0.11 \mathrm{~A} & 4.52 \pm 0.14 \mathrm{AB} & 4.40 \pm 0.76 \mathrm{ABC} & 4.30 \pm 1.12 \mathrm{BC} & 4.14 \pm 1.00 \mathrm{CD} & 3.98 \pm 0.03 \mathrm{DE} & 3.83 \pm 0.14 \mathrm{E} \\ \text { Titratable acidity }(\%) & 0.82 \pm 0.20 \mathrm{E} & 0.85 \pm 0.01 \mathrm{E} & 0.89 \pm 0.11 \mathrm{D} & 0.92 \pm 0.01 \mathrm{CD} & 0.95 \pm 0.11 \mathrm{BC} & 0.98 \pm 0.20 \mathrm{~B} & 1.03 \pm 0.14 \mathrm{~A} \\ \text { TSS }\left({ }^{\circ} \mathrm{Brix}\right) & 13.40 \pm 1.20 \mathrm{~F} & 13.80 \pm 2.01 \mathrm{EF} & 14.20 \pm 0.11 \mathrm{DE} & 14.60 \pm 2.11 \mathrm{CD} & 15.00 \pm 2.20 \mathrm{BC} & 15.3 \pm 1.47 \mathrm{AB} & 15.9 \pm 1.12 \mathrm{~A} \\ \text { Vitamin C }(\mathrm{mg} / 100 \mathrm{~g}) & 10.00 \pm 1.10 \mathrm{~A} & 8.90 \pm 1.06 \mathrm{~B} & 8.40 \pm 0.89 \mathrm{BC} & 8.00 \pm 1.32 \mathrm{C} & 7.40 \pm 0.36 \mathrm{D} & 7.0 \pm 1.01 \mathrm{D} & 6.4 \pm 0.21 \mathrm{E} \\ \text { Total phenolics }(\mathrm{mg} / \mathrm{g}) & 14.98 \pm 1.21 \mathrm{~A} & 14.95 \pm 2.31 \mathrm{AB} & 14.40 \pm 1.45 \mathrm{~B} & 13.90 \pm 2.52 \mathrm{C} & 13.40 \pm 1.48 \mathrm{D} & 12.9 \pm 2.01 \mathrm{E} & 12.2 \pm 1.07 \mathrm{~F} \\ \text { Reducing sugars }(\%) & 6.38 \pm 1.32 \mathrm{~F} & 6.53 \pm 1.78 \mathrm{EF} & 6.68 \pm 2.31 \mathrm{DE} & 6.84 \pm 1.86 \mathrm{CD} & 6.97 \pm 0.44 \mathrm{BC} & 7.13 \pm 1.19 \mathrm{AB} & 7.32 \pm 1.06 \mathrm{~A} \\ \text { Non reducing sugars (\%) } & 2.47 \pm 0.02 \mathrm{~A} & 2.42 \pm 0.20 \mathrm{AB} & 2.35 \pm 0.04 \mathrm{ABC} & 2.28 \pm 0.06 \mathrm{BCD} & 2.23 \pm 0.12 \mathrm{CDE} & 2.17 \pm 0.98 \mathrm{DE} & 2.13 \pm 0.13 \mathrm{E} \\ \text { Total sugars (\%) } & 8.80 \pm 0.43 \mathrm{C} & 9.30 \pm 0.41 \mathrm{BC} & 9.70 \pm 0.53 \mathrm{BC} & 10.20 \pm 0.48 \mathrm{ABC} & 10.60 \pm 1.79 \mathrm{BC} & 10.9 \pm 1.08 \mathrm{AB} & 11.4 \pm 2.11 \mathrm{~A} \\ \text { Antioxidant activity (\%) } & 46.60 \pm 2.14 \mathrm{~A} & 43.02 \pm 1.76 \mathrm{~A} & 39.1 \pm 2.32 \mathrm{C} & 36.20 \pm 2.11 \mathrm{D} & 32.70 \pm 1.09 \mathrm{E} & 29.1 \pm 1.11 \mathrm{~F} & 26.1 \pm 1.20 \mathrm{G}\end{array}$

Data in the table, are the average of T1 to T6 samples. Letters shows means of different treatments and same letters shown a non-significant results while different letters show significant interaction. $(P \leq 0.05)$.

Table 3: Sensory parameters of antioxidant rich RTS beverage during storage.

$\begin{array}{llllllll}\text { Sensory parameters } & \mathbf{0} \text { day } & \mathbf{1 5} \text { days } & \mathbf{3 0} \text { days } & \mathbf{4 5} \text { days } & \mathbf{6 0} \text { days } & \mathbf{7 5} \text { days } & \mathbf{9 0} \text { days } \\ \text { Color } & 7.45 \pm 0.10 \mathrm{~A} & 7.06 \pm 0.21 \mathrm{~A} & 6.60 \pm 0.41 \mathrm{~B} & 6.18 \pm 0.14 \mathrm{C} & 5.70 \pm 0.11 \mathrm{D} & 5.26 \pm 1.14 \mathrm{E} & 4.95 \pm 1.31 \mathrm{E} \\ \text { Flavor } & 6.60 \pm 0.11 \mathrm{~A} & 6.40 \pm 0.12 \mathrm{~A} & 5.80 \pm 0.36 \mathrm{~B} & 5.40 \pm 0.32 \mathrm{C} & 5.00 \pm 0.21 \mathrm{D} & 4.60 \pm 1.20 \mathrm{E} & 4.20 \pm 1.06 \mathrm{E} \\ \text { Taste } & 7.40 \pm 0.10 \mathrm{~A} & 7.00 \pm 013 \mathrm{~B} & 6.60 \pm 0.13 \mathrm{C} & 6.20 \pm 0.15 \mathrm{D} & 5.80 \pm 1.04 \mathrm{E} & 5.40 \pm 0.87 \mathrm{~F} & 5.00 \pm 0.85 \mathrm{G} \\ \text { Overall acceptability } & 7.46 \pm 0.13 \mathrm{~A} & 7.00 \pm 0.31 \mathrm{~B} & 6.60 \pm 0.23 \mathrm{C} & 6.20 \pm 0.01 \mathrm{D} & 5.90 \pm 1.11 \mathrm{E} & 5.50 \pm 1.12 \mathrm{E} & 5.10 \pm 0.14 \mathrm{~F}\end{array}$

Data in the Table, are the average of T1 to T6 samples. Capital letters shows means of different treatments. Same letters show non-significant results while different letters show significant interaction. ( $P \leq 0.05)$.

\section{Statistical analysis}

The data obtained were statistically analyzed by using two factor factorial Completely Randomized Design (CRD) at 5\% level of significance using 8.1 statistical software package while the means were compared by using LSD test as described by Steel et al. (1997).

\section{Results and Discussion}

Results of different chemical attributes and antioxidant 
activity of apple and autumn olive blended beverages are given below.

\section{Effect of treatment and storage on the pH of antioxidant} rich $R T S$ beverages

The $\mathrm{pH}$ of beverage samples decreased in all treatments by increasing concentration of autumn olive in the beverage (Table 1). Gradual decrease in $\mathrm{pH}$ indicates the presence of certain acidic substances in the beverage. Minimum $\mathrm{pH}$ $(3.81 \pm 0.07)$ was observed in $\mathrm{T}_{6}$ while maximum $\mathrm{pH}$ was recorded in $\mathrm{T}_{1}(4.85 \pm 0.12)$. This decrease in $\mathrm{pH}$ might be due to the fact that autumn olive juice is rich source of different organic acids like malic, quinic, citric acid and vitamin C (Gosslau and Chen, 2004). The storage intervals also exhibited significant effect $(\mathrm{p} \leq 0.05)$ on $\mathrm{pH}$ value of product (Table 2). Decreasing trend in $\mathrm{pH}$ was observed in all beverage samples (T1-T6) during storage. This may be due to the increase in various organic acids that include quinic acids, tartaric acid and acetic acid during storage as reported by Sogi and Singh (2001) in kinnow juice that raise level of acidity and hence decreased the value of $\mathrm{pH}$. The result of this research correlates with the findings of Dehbi et al. (2014) that studied pear juice and observed decreasing trend for $\mathrm{pH}$ during storage.

\section{Effect of treatment and storage on the titratable acidity of antioxidant rich RTS beverages}

Maximum value for titratable acidity was noted in $\mathrm{T}_{6}(1.30 \pm 0.02)$ while minimum value was recorded in $T_{1}(0.62 \pm 0.17)$ as presented in Table 1 . Acidity of the beverage sample increased linearly with increasing the concentration of autumn olive in the beverage samples. Minimum acidity $(0.62 \pm 0.17)$ was found in $\mathrm{T}_{1}$ while maximum acidity $(1.30 \pm 0.02)$ was observed in $\mathrm{T}_{6}$. The autumn olive is rich source of various acids that include pentanoic acid, malic acid, tartaric acid, citric acid, octylic acid and ascorbic acid as reported by Veazie et al. (2005) that raise levels of acidity in beverage samples. In current study, an increase in acidity level was also observed in all beverage samples during storage (Table 2) which is due to the formation of acidic compounds and oxidation of reducing sugrars resulting in formation of acidic compounds which raised the acidity level in beverage samples (Iqbal et al., 2001; Mishra et al., 2011; Rivas et al., 2006).
Effect of treatment and storage on the total soluble solids of antioxidant rich RTS beverages

There was non-significant effect of treatments on the TSS contents of all samples (Table 1). However, an increase in TSS contents was observed in samples during storage (Table 2). The hydrolysis of polysaccharides (pectin, cellulose and starch into monosaccharide and oligosaccharides) or sugars fermentation may be the reason for the increased TSS contents during storage (Bhardwaj and Mukherjee, 2011). Moreover, moisture loss during storage also leads to increased TSS contents as reported by Barwal et al. (2005) in bitter gourd fruit juice. The results are linked with Sasikumar et al. (2013) who reported blend of Aloevera, Aonla and Ginger juice and find increasing trend in TSS. Similarly, Deka and Sethi (2001) studied fruit juice and observed similar increasing trend in TSS during storage.

\section{Effect of treatment and storage on ascorbic acid (vitamin C) contents of antioxidant rich RTS beverages}

Vitamin $\mathrm{C}$ content was increased with the increasing concentration of autumn olive in the beverage samples (Table 1). Maximum value of ascorbic acid was noted in $T_{6}(10.6 \pm 0.76)$ whereas minimum value was recorded for $T_{1}(5.8 \pm 1.11)$. This increment may be due to the fact that autumn olive is rich source of vitamin C (Ahmad et al., 2006; Sabir et al., 2007). However, ascorbic acid content of all beverage samples decreased gradually during storage. This decrease may be due to the fact that ascorbic acid is sensitive to heat and is oxidized rapidly in the presence of oxygen hence it might have been demolished during processing and subsequently during the storage period. Similarly, formation of hydroxymethylfurfural (HMF) compounds and degradation of ascorbic acid to carbolic acid, dehydro ascorbic acid furfural and hydroxyl furfural in beverage is communal phenomenon involved in decline of ascorbic acid during storage (Ilamaran and Amutha, 2007; Jain and Khurdiya, 2005).

\section{Effect of treatment and storage on the total phenolics of antioxidant rich $R T S$ beverages}

Total phenolics of beverage samples increased by increasing the concentration of autumn olive in the beverage (Table 1). Maximum value was recorded in $\mathrm{T}_{6}(21.3 \pm 2.01 \mathrm{mgGAE} / \mathrm{g})$ whereas minimum value was recorded in $T_{1}(5.2 \pm 0.32 \mathrm{mgGAE} / \mathrm{g})$. Increase in total phenolics by the addition of autumn olive in beverage samples may be due to the fact that 
autumn olive is rich source of phenolic compounds (Perkins et al., 2005). These results were supported by Leahu et al. (2013) who studied carrot juice mixed with apple and peach juice and mentioned increasing trend of phenolic compounds in different treatments. The results concerning effect of different storage intervals on total phenolics are presented in Table 2 (data in the Table, are the average of $\mathrm{T}_{1}$ to $\mathrm{T}_{6}$ samples). Total phenolics were decreased as the storage period prolonged. This decreasing trend is due to the loss of flavonoids which include catechins, proanthocyanins, anthocyanidins, flavones, and their glycoside. There are five major groups of phenolic compounds in apples that include hydroxycinnamic acids, flavan-3-ols, anthocyanins, flavonols and dihydrochalcones (Khattak, 2012). During storage, some monomeric anthocyanins might have been distorted into polymeric compounds that leads to the reduction of total phenolics as reported by George et al. (2007) in apple juice. The results of this research are in accordance with Klimczak et al. (2007) who reported decreasing trend of total phenolics orange juice during storage period. Likewise, González et al. (2008) and Noci et al. (2008) also reported decreasing trend for total phenolics during storage in lemon and apple juices, respectively.

Effect of treatment and storage on the reducing sugars of antioxidant rich $R T S$ beverages

Reducing sugar content of beverage samples decreased by increasing the concentration of autumn olive (Table 1). Top most value was observed in $T_{1}(7.47 \pm 0.11 \%)$ whereas lower value was recorded in $\mathrm{T}_{6}(4.80 \pm 0.76 \%)$. Decrease in reducing sugar content may be due to the fact that autumn olive is poor source of reducing sugar as compared to apple juice so by addition of autumn olive juice to apple juice, the reducing sugar contents reduces. These results are in line with the findings of Deka et al. (2004) who prepared lime and aonla based blend beverage and reported reduction in reducing sugar. There was continuous increase in reducing sugar in all treatments during storage (Table 2; where the data are the average of $\mathrm{T}_{1}$ to $\mathrm{T}_{6}$ samples).). The gradual increase in reducing sugar may be due to the inversion of non-reducing sugar (sucrose) to reducing sugar (fructose) by acid present in the beverage (Yadav, 2006). The results of this investigation are compatible with Tiwari (2000) who observed similar increasing trend in reducing sugar in guava and papaya blends. Similarly Yadav (2006) studied sweet orange and ummel RTS beverage and reported increasing trend in reducing sugar during storage.

Effect of treatment and storage on the non-reducing sugars of antioxidant rich RTS beverages

Non reducing sugars decreased in all beverage samples (Table 1). Maximum value was noted in $T_{1}$ $(2.70 \pm 0.02 \%)$ while lower value was recorded in $\mathrm{T}_{6}$ $(1.67 \pm 0.01 \%)$. It is evident that non reducing sugar decreased as the concentration of autumn olive increased. Higher value was reported in $\mathrm{T}_{1}(100 \%$ apple juice+ $0 \%$ autumn olive) due to the presence of more non reducing sugar in apple then in autumn olive juice. Sandi et al. (2004) also observed similar decrease of non-reducing sugar in yellow passion fruit juices. Non-reducing sugar decreased during different storage intervals as shown in Table 2 (data in the Table, are the average of $T_{1}$ to $T_{6}$ samples). This decrease in non-reducing sugar might be due to the conversion of non-reducing sugar into reducing sugars like glucose and fructose (Dhaliwal and Hira, 2001). These findings are in line with the findings of Nidhi et al. (2008) who reported decreasing trend of non-reducing sugar in bael-guava blended beverage during storage. Similarly, Dhaliwal and Hira (2001) studied carrot-beet root and carrot-black carrot juices and observed decreasing trend for non-reducing sugar during storage.

Effect of treatment and storage on the total sugars of antioxidant rich RTS beverages

Maximum Value was recorded in $\mathrm{T}_{1}(10.6 \pm 1.04 \%)$ while minimum value was recorded in $\mathrm{T}_{6}(6.4 \pm 1.08 \%)$ as shown in Table 1 . The decrease in total sugar by the addition of autumn olive may be due to the fact that autumn olive juice contain various dominant organic acids and reduced content of total sugar (Malav et al., 2014). Gonzalez et al. (2008) reported decrease in total sugar in different blends of lemon and arona juice. The results regarding the effect of different storage interval on total sugars of beverage sample are presented in Table 2 (data in the Table, are the average of $T_{1}$ to $T_{6}$ samples). The total sugars increased in all samples during storage. The increase in total sugars is due to hydrolysis of polysaccharides like pectin, cellulose, starch into simple sugars (glucose and fructose) and loss of moisture during storage (Malav et al., 2014). The findings are in line with Waskar and Garande (2003) who prepared pomegranate and kokum juice and found similar increasing trend during storage. Similarly, Awsi and Dorcus (2012) studied pineapple juice blend with carrot and orange 
juice and confirmed that total sugars (\%) increased during storage.

Effect of treatment and storage on the antioxidant activity of antioxidant rich RTS beverages

The antioxidant activity of beverage samples increased by increasing the concentration of autumn olive in the beverage samples (Table 1 ).Highest value was recorded in $\mathrm{T}_{6}(50 \pm 1.98 \%)$ while least value was observed in $\mathrm{T}_{1}(24.5 \pm 2.06 \%)$. The increase in antioxidant activity may be due to the fact that autumn olive is rich source of various antioxidants that include vitamin c, lycopene, flavanols and hydroxybenzoic acids (Veazie et al., 2005). The presence of these acidic substances in autumn olive results in increase antioxidant activity of beverage. These results are in line to the findings of Inyang and Abah (2007) that blended orange and apple in different ratios. However, antioxidant activity decreased in all samples with the passage of time (Table 2). The decreasing trend during storage is linked with the fact of lower content of phenolic compounds and vitamin $\mathrm{C}$ that influence antioxidant activity directly. Similarly, Klimczak et al. (2007) studied storage of orange juice and their effect on antioxidant activity and reported decreasing trend activity in juices. In the same way, Franke et al. (2005) studied orange juice and detect that antioxidant activity decreased during storage.

Effect of treatment and storage on the organoleptic evaluation score of antioxidant rich RTS beverage

The sensory quality profile of beverage is a prime factor to consider the marketability of product. During storage, it was observed that overall sensorial quality profile of RTS beverage slightly decreased during storage yet remained under the consideration of "Like very much" by panel members. The color of beverage samples increased by addition of autumn olive (Table 1). The uppermost value was noted in $\mathrm{T}_{6}(7.0 \pm 0.78)$ whereas minimum value was recorded for $\mathrm{T}_{1}(5.2 \pm 1.01)$. The improvement in color may be due to the fact that autumn olive is rich source of various pigments that include $\alpha$-cryptoxanthin, $\beta$-cryptoxanthin, $\beta$-carotene, lutein, phytoene, and phytofluene flavonoids and carotenoids, lycopene (Fordham et al., 2001). These results are in accordance with Tandon et al. (2007) that also reported the addition of papaya pulp with bael pulp very effective in improving the color of the beverage. Earlier work revealed that decrease in color during storage is due to the degradation, oxidative loss of pigments, non- enzymatic browning and presence of oxygen as reported by (Byanna et al., 2013). These results are associated with Naik et al. (2009) who studied whey based watermelon beverage and find decreasing pattern for color during storage (Table 3; where data in the Table, are the average of $\mathrm{T}_{1}$ to $\mathrm{T}_{6}$ samples). Likewise, De-Carvalho et al. (2007) studied coconut water and cashew apple juice and stated that color decreased during storage.

Flavor of RTS beverage increased as the concentration of autumn olive increases upto $60 \%$. Maximum score was recorded in $\mathrm{T}_{4}(6.3 \pm 0.11)$ whereas the minimum value was recorded for $\mathrm{T}_{6}(4.40 \pm 0.14)$ in which concentration of autumn olive was $80 \%$ followed by $100 \%$ (Table 1). It may be due to the fact that autumn olive is rich source of various acids that influence and retard the flavor of the beverage blends. Hence, results in minimum score by the judges. Beverage blends that decreased flavor may be due to loss of flavoring compounds like Ethyl butanoate, $\beta$-myrcene, octanal, linalool, $\alpha$-pinene and decanal (Deka et al., 2005; Maicas and Mateo, 2005; Bhuiyan et al., 2012)

It is evident from the results (Table 1) that taste of beverage increases as the concentration of autumn olive increases up to $60 \%$. This increase in taste of the beverage may be due to the fact that autumn olive is a rich source of various organic acid (Bazemore et al., 2003). Moreover, taste is badly affected by increasing the concentration of autumn olive up to $80 \%$ and $100 \%$. During storage, there was decrease in taste score (Table 3). The decrease in taste might be due to the increase in acidity and production of certain compounds like 3-Hexenal, Linalool and Octanal acids (Bazemore et al., 2003), that results in tartness and sour taste of the beverage samples (Esteve et al., 2005; Poonam and Tandoom, 2007).

The comparison of the different treatment values resulted maximum overall acceptability for $T_{4}$ $(7.46 \pm 1.06)$ as best, whereas minimum value was recorded for $\mathrm{T}_{6}(4.92 \pm 1.74)$ as shown in Table 1 . The beverage sample with $60 \%$ autumn olive and $40 \%$ apple juice showed best acceptable results. Overall acceptability of beverage blends increases as the concentration of autumn olive increases up to $60 \%$. This treatment was considered as the best acceptable by judges because of excellent flavor and taste. Other treatments in which concentration of autumn olive was $80 \%$ and $100 \%$ showed poor results as they were 
high in acidity, tartness and sour in taste. After passage of time decrease in color, flavor, taste and development of certain organic acids like citric and tartaric results in loss of overall acceptability of the beverage (Gowda and Jalali, 2005; Verma and Gehlot, 2007).

\section{Conclusions and Recommendations}

On the basis of above results, it is possible to prepare fruit RTS beverages by blending various fruit juices like apple and autumn olive. Blended drink having $40 \%$ Apple and 60\% autumn olive juice RTS was highly acceptable. It could be stored at ambient condition in PET bottles for 90 days without showing any symptoms of microbial spoilage. Being antioxidant rich, there is a huge potential of autumn olive blended drinks to minimize the issues of degenerative diseases and to replace the already commercially available soft drinks.

\section{Acknowledgment}

The authors acknowledge the The University of Poonch, Rawalakot for the financial support of the present study.

\section{Author's Contribution}

Hamza Tariq performed experiment in lab. Imran Hayat planned and gave the idea. Saima Rafiq supervised and reviewed the experiment. Aqsa Qayyum wrote the manuscript and analyzed data statistically.

\section{Conflict of interest}

The authors have declared no conflict of interest for this article.

\section{References}

Ahmad, S.D., S.M. Sabir and M. Zubair. 2006. Ecotypes diversity in autumn olive (Elaeagnus umbellata Thunb), a single plant with multiple micronutrient genes. Am. J. Chem. Ecology. 22: 509-521. https://doi. org/10.1080/02757540601024819

AOAC. 2006. Association

of official and Analytical Chemists. Official methods of analysis D.C. Washington.

Awsi, J. and M. Dorcus. 2012. Development and quality evaluation of pineapple juice blend with carrot and orange juice. Int. J. Sci. Res. Publ. 2: 60-75.

Ayhan, Z., H.W.Teom, Q.R. Zhang and D.B. Min. 2001. Flavor, color and vitamin $C$ retention of pulsed electric fields processed orange juice in different packaging materials. J. Agric. Food Chem. 49: 669-674. https://doi.org/10.1021/ jf000984b

Barwal, V.S., T.K. Singh and R. Alkesh 2005. Studies on processing and development of ready-to-serve drink from bitter gourd fruit. J. Food Sci. Technol. 42: 217-220.

Baljeet, S.Y., B.Y. Ritika and R. Sarita 2013. Studies on development and storage of whey - based pineapple (Ananascomosus) and bottle gourd mixed herbal beverage. Int. Food Res. J. 20: 607-612.

Bazemore,J.S.,K. Balaswamy,P.P.Rao.,A.Nagender and A. Satyanarayana. 2003. Preparation of sour grap (Vitis vinifera) beverages and evaluation of their storage stability. J. Food Process. Technol. 2: 100-116.

Bhagwan, K. and K. Wadhesh. 2014. Development and Storage of Mango Ginger rts Beverage. Int. J. Food Agric. Vet. Sci. 4: 15-20.

Bhardwaj, R. L. and S. Mukherjee. 2011. Effects of fruit juice blending ratios on kinnow juice preservation at ambient storage condition. Afr. J. Food Sci. 5: 281- 286.

Bhuiyan, M., H. Shams-Ud-Din and M.N. Islam. 2012. Development of functional beverage based on taste preference. Environ. Sci. Natl. Resour. 5: 83-87. https://doi.org/10.3329/jesnr. v5i1.11558

Boyer, J. and R. Liu. 2004. Apple phytochemicals and their health benefits. Nutr. J. 8: 65-71.

Byanna, C.N., D. Gowda and V.K. Rao. 2013. Standardization of sweet orange and pomegranate blended RTS beverage using sugar substitutes. J. Agric. Crop Res. 45: 237243.

Campeanu, G.N. and G. Darjanschi. 2009. Chemical composition of the fruits of several apple cultivars growth as biological crop. Notulae. Botanicae Hortic. Agrob. 37: 161-164.

Collins, J. and P. Perkins-Veazie. 2006. Lycopene from plants to humans. J. Hortic. Sci. 41: 1135-1144. https://doi.org/10.21273/ HORTSCI.41.5.1135

De-Carvalho, J., M. Maia, G.A. De-Figueiredo, R.W. Nubro, De-Brito and S. Rodrigues. 
2007. Development of a blended non-alcoholic beverage composed of coconut water and cashew apple juice containing caffeine. J. Food Qual. 30: 664-681. https://doi.org/10.1111/ j.1745-4557.2007.00149.x

Dehbi, F., A. Hasib, A. Ouatmane, H. Elbatal and A. Jaouad. 2014. Physicochemical characteristics of moroccan prickly pear juice (Opuntia ficus indica L.). Int. J. Emerg. Technol. Adv. Eng. 4: 300-306.

Deka, B.C. and V. Sethi. 2001. Preparation of mixed fruit juice spiced RTS beverages. Indian Food Packer. 42: 58-61.

Deka, B.C., V. Sethi and A. Saikia 2005. Changes in quality of mango-pineapple spiced beverage during storage. Indian J. Hortic. 62: 71-75.

Deka, B., C. Sethi, V. Suneja and V.K. Srivastava. 2004. Physicochemicanl changes of lime and aonla spiced blend beverage during storage. J. Food Sci. Technol. 41: 329-332.

Dhaliwal, M. and K.C. Hira. 2001. Effect of storage on physico-chemical and nutritional characteristics of carrot-beet root and carrotblack carrot juices. J. Food Sci. Technol. 38: 343-347.

Esteve, M.J., A. Frigola, C. Rodrigo and D. Rodrigo. 2005. Effect of storage period under variable conditions on the chemical and physical composition and colour of Spanish efrigerated orange juices. Food Chem. Toxi. 43: 1413-1422. https://doi.org/10.1016/j.fct.2005.03.016

Fordham, I., M. Zimmerman, R.H. Black, B.I. Clevidence and E.R. Wiley. 2003. Autumn olive: A potential alternative crop. Acta Hortic. 626: 437-439. https://doi.org/10.17660/ ActaHortic.2003.626.59

Fordham, I., B.E. Clevidence and R. Zimmerman. 2001. Fruit of autumn olive a rich source of lycopene. J. Horti. Sci. 36: 1136-1137. https:// doi.org/10.21273/HORTSCI.36.6.1136

Franke, A., R. Cooney, S.M. Henning and L.J. Custer. 2005. Bioavailability and antioxidant effects of orange juice components in humans. J. Agric. Food Chem. 53: 5170-5178. https:// doi.org/10.1021/jf050054y

George, A., E. Wroistad and D.A. Heatherbel. 2007. Influence of processing and storage on the phenolic composition of apple juice. J.Agric. Food Chem. 38: 1572-1579. https:// doi.org/10.1021/jf00097a031

Gonzalez, E., D.A. Moreno and G. Viguera. 2008.
Aronia-enriched lemon juice. A new highly antioxidant beverage. J. Agric. Food Chem. 56: 11327-11333. https://doi.org/10.1021/ jf802790h

Gosslau, A. and K.Y. Chen. 2004. Nutraceuticals apoptosis and disease preventation. J. Nutr. 20: 95-102. https://doi.org/10.1016/j. nut.2003.09.017

Gowda, I.N. and S. Jalali. 2005. Studies on juice making from watermelon juice. Indian Food Packer. 49: 33-35.

Guo, X.L., L. Yang, H.T. Hu and L. Yang. 2009. Cloning and expression analysis of carotenogenic genes during ripening of autumn olive fruit. J. Agric. Food Chem. 57: 5334-5339. https://doi. org/10.1021/jf900547e

Ilamaran, M. and S. Amutha. 2007. Effect of total soluble solids and $\mathrm{CO}_{2}$ pressure on physicochemical and sensory qualities of carbonated banana and sapota beverages. J. Food Sci. Technol. 44: 178-82.

Inyang, U.E. and U.J. Abah. 2007. Chemical composition and organolepti evaluation of juice from steamed cashew apple blended with orange juice. Plant Foods Hum. Nutr. 50: 295300. https://doi.org/10.1007/BF02436076

Iqbal, S., A. Yasmin, S. Waduad and W.H. Shah. 2001. Production, storage, packaging and quality evaluation of guava nectar. Pak. J. Food Sci. 11: 33-36.

Jain, S.K., and D.S. Khurdiya. 2005. Vitamin 'C 'enrichment of fruit juice based ready-toserve beverages through blending of Indian gooseberry juice. Plant Foods Human Nutr. 59: 63-70. https://doi.org/10.1007/s11130-0040019-0

Khattak, F.K., 2012. Free radical scavenging activity, phytochemical composition, and nutrient analysis of Elaeagnus umbellata berry. J. Med. Plant Res. 6(39): 5196-5203. https://doi. org/10.5897/JMPR11.1128

Klimczak, I., M. Malecka and A. Gliszcynska. 2007. Effect of storage on the content of polyphenols, vitamin $\mathrm{c}$ and the antioxidant activity of orange juices. J. Food Compos. Anal. 20: 313-322. https://doi.org/10.1016/j.jfca.2006.02.012

Koutsos, A. and J.A. Lovegrove. 2015. Interrelationship between apple consumption, the gut microbiota and cardiometabolic disease risk reduction. Academic Press, Elsevier: London, UK. pp. 173-194. https://doi.org/10.1016/ 
B978-0-12-407825-3.00012-5

Larmond, E., 1977. Laboratory methods of sensory evaluation of foods. Publication no-1673. Dep. Agric., Ottawa. canada.

Leahu, A., C. Damia, N. Carpiuc, M. Oroian and M. Avramiuc. 2013. Change in colour and physicochemical quality of carrot juice mixed with other fruits. J. Agroaliment. Processes Technol. 19: 241-246.

Maicas, S. and J.J. Mateo. 2005. Hydrolysis of terpenyl glycosides in grape juice and other fruit juices. Appl. Microbiol. Biotechnol. 67: 322-335. https://doi.org/10.1007/s00253-0041806-0

Malav, D., M.S. Jakhar and S. Pathak. 2014. Studies on the preparation and storage stability of blended ready-to-serve from ber (Zizyphus mauritiana lamk.) and jamun (Syzigium cuminii skeels.) pulp. Plant Arch. 12: 533-536.

Minhas, F.A., H.U. Rehaman, A. Yasin, Z.I. Awan and N. Ahmed. 2013. Antimicrobial activities of the leaves and roots of Elaeagnus Umbellata. Afr. J. Biotechnol. 12: 6754-6760. https://doi. org/10.5897/AJB11.4181

Mishra, B., S. Gautam and A. Sharma. 2011. Shelf life extension of sugarcane juice using preservatives and gamma radiation processing. J. Food Sci. 76: 573-578. https://doi.org/10.1111/ j.1750-3841.2011.02348.x

Naik, Y., K. Khare, A. Choudhary, P.L. Goel and B.K. Shrivastav. 2009. Studies on physicochemical and sensory characteristics of whey based watermelon beverage. Asian J. Res. Chem. 2: 57-59.

Nidhi, R., R. Gehlot and M.K. Rana.2008. Changes in chemical composition of ready-to-serve of bael-guava blended beverage during storage. J. Food Sci. Technol. 45: 378-380.

Noci, F., J. Riener, M.W. Ribeiro, D.A. Cronin, D.J. Morgan and J.G. Lyng. 2008. Ultraviolet irradiation and pulsed electric fields (PEF) in a hurdle strategy for the preservation of fresh apple juice. J. Food Eng. 85: 141-146. https:// doi.org/10.1016/j.jfoodeng.2007.07.011

Ntakyo, P.R.,J.Mugisha and G.Elepul.2015. Socioeconomic factors affecting apple production in southwestern Uganda. Afr. Crop Sci. J., 21: 311- 321.

Parmar, C. and M. Kaushal. 1982. Wild Fruits of (Elaeagnus umbellata) in Sub-Himalayan regions. Kalyani Publishers. New Delhi, India, pp. 23-25

Perveen, R., H. Suleria, F. Anjum, P. But, I. Pasha and S. Ahmad. 2015. Tomato (Solanum lycopersicum) carotenoids and lycopenes chemistry; metabolism, absorption, nutrition and allied health claims, $A$ comprehensive review. Crit. Rev. Food Sci. Nutr. 55: 919-929. https://doi.org/10.1080/10408398.2012.65780 9

Perkins-Veazie, P.M., B.L. Black, I.M. Fordham and L.R. Howard. 2005. Lycopene and total phenol content of autumn olive (Elaeagnus umbellata) selections. Hortic. Sci. 40: 883-893. https://doi. org/10.21273/HORTSCI.40.3.883f

Petruzzi, L., D. Campaniello, B. Speranza, Corbo, M.R., M. Sinigaglia and A. Bevilacqua. 2017. Thermal Treatments for Fruit and Vegetable Juices and Beverages: A Literature Overview. Comp. Rev. Food Sci. Food Saf. 16: 668-691. https://doi.org/10.1111/1541-4337.12270

Pinto, C., B.R. Galdon, J.J. Cestero and P. Macias. 2013. Hepatoprotective effects of lycopene against carbon tetrachloride-induced acute liver injury in rats. J. Fun. Food. 5: 1601-1610. https://doi.org/10.1016/j.jff.2013.07.002

Poonam, M. and D.K. Tandon. 2007. Development of guava-aonla blended beverage. Acta Hortic. 735: 555-560. https://doi.org/10.17660/ ActaHortic.2007.735.72

Rivas, A., D.A. Rodrigo, G. Martinez, V. Canvoas and M. Rodrigo. 2006. Effect of PEF and heat pasteurization on the physical-chemical characteristics of blended orange and carrot juice. Food.Sci. Technol.39: 1163-1170. https:// doi.org/10.1016/j.lwt.2005.07.002

Sabir, M.S., S.D. Ahmad and N. Lohdi. 2003. Screening of 16 poisonous plants for antibacterial, anthelmintic and cytotoxic activity in vitro. South Afri. J. Bot. 69: 587-592.

Sabir, S.M., S.D. Ahmad, I.M. Hussain and K.M. Tahir. 2007. Antibacterial activity of Elaeagnus umbellata (Thunb.) a medicinal plant from Pakistan. Saudi Med. J. 28: 259-263.

Sandi, D., B.P. Jose, C.G. Antonio, F.M. June, T.C. Marco and B.L. Patricia. 2004. Hunter color dimensions, sugar contents and volatile compounds in pasteurized yellow passion fruit juice during storage. J. Food. Sci. 47: 233-245. https://doi.org/10.1590/S151689132004000200011

Sasikumar, R., R.C. Ray, K.P. Prodyut and C.P. 
Suresh. 2013. Development and storage studies of Therapeutic ready-to-serve made from blend of Aloe vera, Aonla and ginger juice. Food Process. Technol. 4: 6-10. https://doi. org/10.4172/2157-7110.1000232

Shakir, I., Y. Durrani, I. Hussain, I. M. Qazi and A. Zeb. 2008. Physico-chemical analysis of apple and pear mixed fruit jam prepared from varieties grown in Azad Jammu and Kashmir. Pak. Nutr. J. 7: 177-180.

Singleton, V.L., R. Orthofer and R.M. LamuelaRaventos. 1999. Analysis of total phenols and other oxidation substrates and antioxidants by means of folin-ciocalteu reagent. Methods Enzymol. 299: 152-178. https://doi. org/10.1016/S0076-6879(99)99017-1

Sluis, V. D., M. Dekker, G. Skrede and W. M. F. Jongen. 2002. Activity and concentration of polyphenolic antioxidants in apple juice. J. Agric. Food Chem. 50: 7211-7219.

Sogi, D.S. and S. Singh. 2001. Studies on bitterness development in kinnow juice, ready-to-serve beverage, squash, jam and candy. J. Food. Sci. Technol. 38: 433-438.

Steel, R.G.D., J.H. Torrie and D.A. Dicky. 1997. Principle and procedure of statistics, a biometerical approach $3^{\text {rd }}$ Ed. McGraw Hill Book Co. Inc., New York, USA. pp. 400-428.

Sun, J., Y.F. Chu., X. Wu and R.H. Liu. 2002. Antioxidant and antiproliferative activities of fruits. J. Agric. Food Chem. 50: 7449-7454. https://doi.org/10.1021/jf0207530

Tandon, D.K., S. Dikshit and D.K. Shukla. 2007. Storage study on bael-papaya blended RTS beverage. Indian Food Packer. 73: 91-97.

Tiwari, R.B., 2000. Studies on blending of guava and papaya pulp for RTS beverages. Indian Food Packer. 54: 68-72.
Veazie, P.M., B.L. Black and I.M. Fordham and L.R. Howard. 2005. Lycopene and total phenol content of autumn olive (Elaeagnus Umbellata) Selections. J. Hortic. Sci. 40: 883-888. https:// doi.org/10.21273/HORTSCI.40.3.883f

Verma. S. and R. Gehlot. 2007. Studies on development and evaluation of ready-to-serve (RTS) drink from bael (Aegle marmelos Correa). Res. Crops. 8: 745-748.

Vinson,J., X. Su, L. Zubik and P. Bose. 2001. Phenol antioxidant quantity and quality in foods fruits. J. Agric. Food Chem. 49: 5315-5321.

Wang, S.Y. and I.M. Fordham. 2007. Differences in chemical composition and antioxidant capacity among different genotypes of autumn Olive (Elaeagnus umbellata). Food Technol. Biotechnol. 45: 402-409.

Waskar, D.P. and V.K. Garande. 2003. Studies on blending of pomegranate and kokum juices. Bev. Food World. 30: 27-28.

Williams, B.W. and M.E. Cuvelier and C. Berset. 1995. Use of a free radical method to evaluate antioxidant activity. Lebensm.-Wiss Technol. 28: 25-30. https://doi.org/10.1016/S00236438(95)80008-5

Wojdylo, A., J. Oazmianski and P. Laskowski. 2008. Polyphenolic compounds and antioxidant activity of new and old apple varieties. J. Agric. Food. Chem. 56: 6520-6530. https://doi. org/10.1021/jf800510j

Wu, J., H. Gaob, L. Zhaoa, X. Liaoa, F. Chena, Z. Wanga and H. Xiaosong. 2007. Chemical compositional characterization of some apple cultivars. Food Chem. 103: 88-93.

Yadav, N., 2006. Development of rind peeler for pomelo (Citrus grandis) and development of value added products from pomelo fruit. Mysore J. Agric. Sci. 43: 249-254. 